\title{
O GUARDIÃO DE HISTÓRIAS DO VALE DOS DINOSSAUROS E OS SABERES DA TRADIÇÃO: UM RELATO DE EXPERIÊNCIA DE EXTENSÃO UNIVERSITÁRIA NO ALTO SERTÃO DA PARAÍBA
}

\author{
THE GUARDIAN OF STORIES OF THE DINOSAUR VALLEY AND \\ TRADITIONAL KNOWLEDGE: A REPORT OF UNIVERSITY \\ EXTENSION EXPERIENCE IN THE HIGH SERTAN OF PARAÍBA
}

Luan Gomes dos Santos de Oliveira ${ }^{1}$

\begin{abstract}
RESUMO
Este artigo é fruto das vivências em um projeto de extensão, que tinha como título "Alice no país dos dinossauros". Configurou-se como uma proposta de estudo das memórias do guardião do Vale dos Dinossauros - Robson Marques - da cidade de Sousa, alto sertão da Paraíba durante os anos de 2015 a início de 2019. Esse guardião é cronista, poeta, artista plástico, cordelista e paleontólogo da tradição. Essa proposta foi submetida ao Edital de extensão universitária da Universidade Federal de Campina Grande - UFCG. Seu público alvo eram algumas escolas estaduais e municipais do município acima referido, dentre elas a Escola Estadual Júlio Sarmento, a Escola Estadual Batista Leite, e a Escola Municipal de Educação Infantil e Fundamental Maria Aurita. Dentre as atividades extensionistas estavam o teatro popular acerca da Vida de Robson Marques e de suas ideias sobre o Vale dos dinossauros, oficinas de saberes nas escolas, e proposição de um currículo complexo em que se insira em algumas disciplinas da formação básica dos estudantes a temática dos saberes da tradição e do conhecimento produzido pelo guardião. A base epistemológica que norteia esse estudo são: Lévi-Strauss, Conceição Almeida, Edgar Morin e Paulo Freire. Partindo dos diálogos desses autores e das práticas educativas em movimento empreendidas pelos estudantes compreendemos que há uma necessidade de aliança e de religação entre saberes científicos e saberes da tradição. Assim, talvez possamos chegar a uma compreensão mais ampla de Educação, uma noção de Educação em que se leve a totalidade do humano e combata as fragmentações dos saberes ora em vigor.
\end{abstract}

Palavras-chaves: Saberes da tradição; Currículo vivencial e complexo; Práticas Educativas em movimento.

\section{ABSTRACT}

This article is the result of experiences in an extension project, which had the title "Alice in the country of the dinosaurs". It was set up as a study proposal of the memories of the guardian of the Valley of the Dinosaurs - Robson Marques - of the city of Sousa, high sertão of Paraiba during the

\footnotetext{
${ }^{1}$ Doutor em Educação pela UFRN. Mestre em Desenvolvimento e Meio Ambiente pela UFRN. Atualmente é Professor da Universidade Federal de Campina Grande - UFCG. e-mail: luangomessantos@terra.com.br
} 


\section{Revista
Debates Insubmissos}

years of 2015 to the beginning of 2019. This guardian is chronicler, poet, plastic artist, cordelista and paleontologist of the tradition. This proposal was submitted to the Federal University Extension of Campina Grande - UFCG. Its target public were some state and municipal schools of the municipality referred to above, among them the Júlio Sarmento State School, the Batista Leite State School, and the Municipal School of Early Childhood Education and Fundamental Maria Aurita. Among the extension activities were the popular theater about the Life of Robson Marques and his ideas about the Valley of the dinosaurs, workshops of knowledge in the schools, and proposition of a complex curriculum in which it is inserted in some disciplines of the basic training of the students thematic the knowledge of tradition and the knowledge produced by the guardian. The epistemological base that guides this study are: Lévi-Strauss, Conceição Almeida, Edgar Morin and Paulo Freire. Starting from the dialogues of these authors and the educational practices in movement undertaken by students, we understand that there is a need for alliance and reconnection between scientific knowledge and traditional knowledge. Thus, perhaps we can arrive at a broader understanding of Education, a notion of Education in which the totality of the human is taken and the fragmentations of the knowledge in force in force.

Keywords: Knowledge of tradition; Experiential and complex curriculum; Educational practices in motion.

\section{INTRODUÇÃO}

Primeiras pegadas...

Esse artigo é resultado da realização de projeto de extensão universitária, constituído pelas memórias do intelectual da tradição Robson Marques que trabalha como Guardião do Vale dos Dinossauros em Sousa - PB, pelas escolas municipais e estaduais e pela Universidade Federal de Campina Grande. As atividades de extensão foram estendidas durante o ano de 2015. Destaca-se, com esta proposta, a sua relevância social que divulga e envolve a população sousense da necessidade de preservação e defesa do patrimônio histórico que é o Vale, esse só possui sentido no contexto das vivências daqueles que constroem a história da cidade de Sousa. Como relevância acadêmica pode-se perceber a importância da Universidade no cumprir de seu ethos, se manter como um canal de diálogo com a sociedade e com os conhecimentos produzidos por outros atores.

Acredita-se que mediante a importância da preservação do Vale, o mais importante é o despertar das memórias vivas a partir de Robson Marques, o Guardião, buscando observar as histórias, contos, poesias, mitos de sua autoria e numa postura de autoformação estar em contato direto e dialógico com as escolas municipais, a sociedade e a Universidade. Portanto, o interesse é cooperar com o envolvimento dos atores na construção coletiva da extensão 
universitária capaz de projetar, escolher, abraçar, expandir, dialogar e criar. Sendo um tema emergente de valorização da cultura popular do sousense, da promoção de preservação do patrimônio histórico-cultural do Vale e da inserção de saberes populares no currículo das escolas municipais/estaduais e universidade.

Os objetivos das ações desse projeto foram o de promover a valorização dos saberes da tradição produzidos nos meandros do Vale dos Dinossauros, por meio das memórias do velho do rio (Robson Marques) considerando a necessidade de maior divulgação e conhecimento sobre a importância da preservação deste patrimônio histórico-cultural junto às escolas municipais de Sousa-PB. Divulgar os saberes da tradição inclusos na formação de histórias do Guardião Robson Marques sobre Vale dos Dinossauros em unidade com as escolas. Estabelecer uma relação de histórias de vida, narrativas sobre o Vale, com a sociedade sousense para conhecer a sua participação na preservação deste patrimônio histórico nacional. Construir uma cultura extensionista e dialógica capaz de criar outros saberes que visem a transformação dos sujeitos em relação. E para isso tomamos como base epistêmica a compreensão de Almeida, (2001, p. 21) sobre a extensão universitária,

[...] é em grande parte o espaço do perigo e da incerteza, porque não faz uso da burocracia do conceito e da avaliação normativa. Nisso está seu potencial como o lugar da respiração da instituição universitária, como um espaço aberto para dicionarizar novos diálogos, capazes de projetar uma nova universidade para um novo mundo, capaz de refundar, como quer Morin, uma "Civilização das Ideias". É pela via da extensão, do sair de si, que o conhecimento pode dialogar com o mundo do qual fala. Estender os braços é um dever da universidade, entretanto, o abraço com ética e estética do pensamento complexo, está longe de ser insípido e acéptico. Ele é simultaneamente inocente e libertino. Contém doses antagônicas e complementares de intemperança, parcimônia, excessos, ludicidade e compaixão. É um abraço quase uterino, que sabe nutrir e conter, mas somente na condição de facilitar o momento da necessária expulsão para outro patamar de vida. Projetar, escolher, fazer. Abraçar. Expandir. Esse é o desafio da face extensiva da universidade.

O público alvo deste trabalho são as escolas que fazem parte da Rede Municipal e Estadual do Município de Sousa /PB. Envolvendo discentes e docentes de duas escolas estaduais e uma municipal na fase do Ensino Médio e Fundamental, dentre elas, a Escola Estadual Júlio Sarmento, a Escola Estadual Batista Leite, a Escola Municipal Maria Aurita. A participação dos estudantes de séries do ensino médio e da educação infantil foi relevante para 
a construção da extensão universitária enquanto um espaço de diálogo de saberes e de práticas educativas em movimento.

\section{OS SABERES DA TRADIÇÃO COMO OPERADORES DA PRÁTICA EDUCATIVA DE DIÁlOGO COM O MUNDO}

Quero transmitir a necessidade de resistir à tentação de uma oposição brutal entre as ciências e os saberes chamados de "não-científicos", cuja articulação será necessária se tivermos de aprender como responder ao que já começou.

Isabelle Stengers

A experiência desse projeto de extensão apostou na dialógica entre saberes da tradição e saberes científicos, como bem expressou a pensadora Isabelle Stengers, de que a necessidade desse diálogo entre saberes se põe como uma realidade para o diálogo com o mundo. Quem mais tratou desse diálogo e o encarnou na educação como uma experiência viva foi o educador Paulo Freire. Para ele,

A educação tem sentido porque o mundo não é necessariamente isto ou aquilo, porque os seres humanos são tão projetos quanto podem ter projetos para o mundo. A educação tem sentido porque mulheres e homens aprenderam que é aprendendo que se fazem e se refazem, porque mulheres e homens se puderam assumir como seres capazes de saber, de saber que sabem, de saber que não sabem. De saber melhor o que já sabem, de saber o que ainda não sabem. A educação tem sentido porque, para serem, mulheres e homens precisam de estar sendo. Se mulheres e homens simplesmente fossem não haveria porque falar em educação. É neste sentido que mulheres e homens interferem no mundo enquanto os outros animais apenas mexem nele. É por isso que não apenas temos história, mas fazemos a história que igualmente nos faz e que nos torna portanto históricos (FREIRE, 2000, p. 40).

É dessa maneira que concebemos os saberes da tradição, como saberes históricos, tecidos na trama das experiências e vivências de homens, mulheres e comunidades que se destacam na composição de saberes diversos sobre o mundo em que habitam. Edgar Morin tece uma reflexão sobre Tradição no prefácio do livro "Cosmologias e Saberes da Tradição de autoria de Maria da Conceição de Almeida. Ele afirma que há uma tensão histórica entre os saberes da tradição e os saberes científicos, especialmente no seio da ciência clássica. "A tradição não deve ser rejeitada como superstição e nem exaltada como conhecimento primordial. Quando, entretanto, se reflete sobre o humano, a origem não deve ser 
compreendida como um conhecimento balbuciante, simples e grosseiro. A noção de saberes da tradição desta pesquisa, tem como base epistemológica a matriz de pensamento de Maria da Conceição de Almeida, Antropóloga e umas das pensadoras das ciências da complexidade. Por compreender que esta

[...] matriz argumentativa - a tese de doutorado Complexidade e Cosmologias da Tradição (ALMEIDA, 1992). Essa matriz desdobra-se em dois eixos norteadores. O primeiro atinente à pesquisa na Lagoa do Piató, consolida argumentos e abre novos caminhos investigativos. O segundo eixo, fruto da ancoragem anterior, oferece subsídios e bases epistêmicas para projetos de mestrado, doutorado e monografias sob a orientação de pesquisadores do Grecom. (ALMEIDA, 2010, p. 59)

Essa pesquisa mantém-se conectada a outras constelações de pensamento: Claude Lévi-Strauss, Edgar Morin, Francisco Lucas da Silva, Georges Balandier, Daniel Munduruku. Partindo desse marco, a noção de saberes da tradição é histórica. Possui uma história, uma origem. Porém, não é o objetivo desse texto encontrar a arké. A direção pretendida é escavar, buscando identificar as diversas camadas que constituem os saberes da tradição. Tomando emprestado as palavras de Edgar Morin, considero esta pesquisa como uma sociologia do conhecimento, propondo-se a estudar as condições históricas e culturais de emergência dos saberes da tradição.

A concepção de ciência da tradição compreende "o homem enquanto um ser biológico ao mesmo tempo em que um indivíduo social” (LÉVI STRAUSS, 2012, pág. 39). Tal compreensão rompe com a dualidade entre natureza e cultura. O ser humano ao mesmo tempo é cultura, é natureza. No entanto, as ciências modernas datadas do século XVII cooperaram com a fragmentação dos conhecimentos em disciplinas que não se dialogam. Essa condição percebe que os domínios do conhecimento fraturam cada vez mais a noção de antropos.

Essa condição imanente ao "sapiens-demens" indica que o conhecimento científico se distanciou da vida porque acreditou ser a única possibilidade da razão. Ao contrário da explicação científica, a "ciência" da tradição leva em conta as relações subjetivas, sensíveis e "des-racionais" como fundamentais para os entendimentos dos processos sócio-culturais. Esse caráter unitário do pensamento que Lévi-Strauss já havia postulado teórica e epistemologicamente, parece desaparecer no corpus da produção analisada. Isso talvez seja fruto da divisão entre tradição e ciência... Essa arrogância da ciência ao se supor o nível mais avançado de leitura da realidade, inscreve-se na problemática da divisão e especialização do processo de conhecimento que, sem dúvida, extrapolando os estreitos limites internos da ciência, contaminou a "realidade", seccionando-a e dividindo-a entre os proprietários e os não proprietários do saber instituído. (ALMEIDA, 1992, p. 179-181). 


\section{Revista \\ Debates Insubmissos}

A concepção conhecimento, como uma aptidão universal na humanidade e no mundo vivo, como produto da cultura em Almeida está embasada na compreensão de que “[...] a história do conhecimento científico é bastante curta para que estejamos bem informados a seu respeito; mas o fato de que a ciência moderna remonta somente a alguns séculos coloca um problema sobre o qual os etnólogos ainda não refletiram suficientemente: o nome de paradoxo neolítico the conviria perfeitamente" (LÉVI-STRAUSS, 2012, p. 30). E quanto a esse paradoxo ainda podemos concluir que:

O homem neolítico ou da proto-história foi, portanto, o herdeiro de uma longa tradição científica; contudo, se o espírito que o inspirava, assim como a todos os seus antepassados, fosse exatamente o mesmo que o dos modernos, como poderíamos entender que ele tenha parado e que muitos milênios de estagnação se intercalem, como um patamar, entre a revolução neolítica e a ciência contemporânea? O paradoxo admite apenas uma solução: é que existem dois modos diferentes de pensamento científico, um e outro funções, não certamente estádios desiguais do desenvolvimento do espírito humano, mas dois níveis estratégicos em que a natureza se deixa abordar pelo conhecimento científico - um aproximadamente ajustado ao da percepção e ao da imaginação, e outro deslocado; como se as relações necessárias, objeto de toda ciência, neolítica ou moderna pudessem ser atingidas por dois caminhos diferentes: um muito próximo da intuição do sensível e o outro mais distanciado. (LÉVI - STRAUSS, 2012, p. 31)

O modo de pensar dos povos taxados de "primitivos" possue autonomia em sua ciência primeira, também chamada de bricolage, quando percebidos em relação ao pensamento domesticado ocidental. Pode ser considerada um pensamento selvagem que não está distante de nós ocidentais, Lévi-Strauss faz uso da metáfora do engenheiro e do bricoleur para expor os dois tipos de conhecimento científico.

O bricoleur está apto a executar um grande número de tarefas diversificadas, porém, ao contrário do engenheiro, não subordina nenhuma delas à obtenção de matérias primas e de utensílios... isto é um conjunto de sempre finito de utensílios e de materiais bastante heteróclitos... Em nossos dias, o bricoleur é aquele que trabalha com suas mãos, utilizando meios indiretos se comparados com os do artista... Para o bricoleur trata-se de mensagens forma pré-transmitidas e que ele coleciona...Já o homem de ciência, engenheiro ou físico antecipa sempre a outra mensagem que poderia ser arrancada a um interlocutor, apesar de sua relutância em se pronunciar a respeito de questões cujas respostas não foram dadas anteriormente. (LÉVISTRAUSS, 2012, p. 37)

Diante da distinção necessária entre os dois modos de pensamento científico. Vale enfatizar a importância de combater a superposição de ciência sobre tradição e vice-versa. Há a necessidade de dissolver o homem na natureza. 


\title{
norstat 0 \\ Debates Insubmissos
}

Uma tal dissolução, que tem valor analítico de um operador de método, deve entretanto satisfazer duas condições: em primeiro lugar não empobrecer os fenômenos submetidos a redução; em segundo lugar assegurar, previamente, que se reuniu em torno do fenômeno tudo o que contribui para sua riqueza e originalidades distintivas. (ALMEIDA, 2012, p. 119).

Compreendemos então que a Ciência não cortou o seu cordão umbilical com o que da ordem das experiências sociais e culturais. Sendo assim, pode-se perguntar de que modo a escola pode ampliar práticas pedagógicas que religue ciência e tradição, vida e ideias? Assumindo uma concepção de ciências como produto da cultura humana. De forma a ter uma resposta mais ampla e complexa Almeida argumenta:

\begin{abstract}
Os conteúdos hoje transmitidos pela ciência correspondem a uma história domesticada das descobertas do homem. Está fora de circulação a diversidade de explicações, especulações e métodos de olhar, classificar e hierarquizar os fenômenos do mundo, pelos intelectuais da tradição. São os métodos científicos de previsão climática que são comunicados na escola, e nunca as formas tradicionais de leitura do ecossistema pelos peritos da tradição. O exercício do pensamento analógico, ferramenta mental tão fecunda nos saberes não-científicos, é entendido como um atributo mental balbuciante e ingênuo, isto quando não é ostensivamente desclassificado. Se, nos conteúdos escolares, há alusão a outras interpretações do mundo, a elas são imputadas as qualidades de um saber sem rigor, sem método, sem função, um saber menor. Essa forma de interdito na circulação da cultura consolida uma sociedade de múltiplas exclusões e condena as populações não letradas a redutos cada vez mais fechados. Dotados, entretanto, de uma criatividade nãodomesticada, essas populações têm respondido a desafios que talvez a ciência fosse incapaz de enfrentar, se fosse desprovida de tantas ferramentas, artifícios e próteses (ALMEIDA, 2001, p. 583-584).
\end{abstract}

A necessidade de um pensamento complexo que religue e garanta o princípio unitas multiplex para pensar o homem, a ciência, a natureza, como unidade e diversidade. Dessa forma, o que distingue os povos sem escrita (pejorativamente chamados de analfabetos) dos povos dito civilizados? Pode-se empreender que a base de tal interrogação está associada ao fato da ciência moderna ter se afastado de sua fonte primeira. Talvez seja isso, em que consiste o paradoxo do neolítico que tanto Lévi-Strauss fala na obra o pensamento selvagem. É a mesma condição humana que nos universaliza e particulariza. Tendo em vista que saber local, saber global, são formas de olhar o mundo, há a necessidade de uma compreensão da tradição como um fenômeno de ordem complexa, não apenas de natureza local, mas local e global. Daniel Munduruku nos convida a olhar e ouvir os saberes da tradição como potenciais para uma educação além do mercado. 


\title{
3. A INTERFACE SABERES DA TRADIÇÃO E ESCOLA
}

A escola é uma das instituições mais próximas da vida em sociedade. Porém ao longo dos anos a escola tem se distanciado do cotidiano, das experiências vividas, da cultura, e se petrificado no mundo dos conteúdos, distantes da vida dos alunos. Em vez de ser o lugar de pensar bem, torna-se por vezes como um local de domesticação de mentes. A arte, a poesia, eixos importantes da imaginação e da criatividade são relegados a explicação simplista: é lazer, não é conhecimento. A Ciência em vez de ser compreendida como um elemento narrativo de explicação da vida, por vezes é tratada como dogma.

Por isso, a escola precisa reacender a sua dimensão plural, cultural, a partir do diálogo com os saberes da tradição. Pois, esse diálogo amplia as diversas interpretações sobre um mesmo fenômeno. Geralmente nas escolas há a classificação entre o que é científico e o que não é científico. Esse último, visto pejorativamente como balbuciante, menos importante que os ditos científicos. Essa convenção criada pelos departamentos e comunidades acadêmicas cooperou com a fragmentação do Humano da Vida. Assim, a Ciência não é a única forma de explicação da realidade, é uma dentre tantas explicações. Sendo assim,

\begin{abstract}
A ausência de saberes não-científicos na sala de aula gera verdades unitárias, porque se referem somente ao conteúdo passado pelo conhecimento escolar, o que fomenta nas mentes jovens, e depois nos adultos, o sentimento de intolerância contra qualquer outra coisa que não lhes seja familiar ou que julguem estranha. Vale a pena lembrar que a polifonia de interpretações sobre o mundo facilita uma razão aberta e inibe a intolerância. Isso tem uma relação com o sentimento de verdade. (ALDEMIR, 2006, p. 21)
\end{abstract}

A aliança entre os saberes da tradição e a escola é relevante pois abre essa para uma formação contextual, que inclui o sujeito em sua narrativa, e que permite a metamorfose da ciência rumo a uma compreensão complexa do mundo, tomando como horizonte a totalidade da vida social. Os saberes da tradição estão inscritos em histórias dinâmicas que ao longo do tempo são alargadas em suas bases pelos contadores de histórias, pelos criadores da história. Esses saberes tradicionais foram apreendidos historicamente como inferiores aos saberes científicos, sendo que estes são saberes que operam também dentro de uma tradição e que se servem dos saberes tradicionais sem dar o seu reconhecimento. No entanto, já existem 


\section{novist

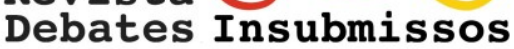

estudiosos como Conceição Almeida, Paulo Freire, Edgar Morin, Carlos Aldemir que investem suas atenções na complementaridade desses saberes. Dessa maneira,

A exclusão dos saberes da tradição na escola mascara o campo de tensão tão fundamental para a espécie humana inscrita nas diversas interpretações sobre um mesmo fenômeno humano. A variação de domínios e explicações pode criar novas interpretações, sem necessariamente excluir e hierarquizar os saberes. Interpretações antagônicas entre si, podem ser, quase sempre, complementares. Uma polifonia de dizeres sobre o mundo favorece um pensamento complexo que encoraja a ação e reconhece a incerteza. Não há verdade absoluta; as verdades se contrapõem, elas são opostas e complementares. O campo tensional entre a escola, como transmissora do conhecimento oficial, e a tradição, como detentora de um saber milenar, provoca nos sujeitos o direito a outras verdades, sem, necessariamente, negar a verdade contrária para se afirmar. Isso faz lembrar uma proposição da lógica, segundo a qual a negação de uma proposição falsa gera uma proposição verdadeira. É nesse campo tensional que este livro discute a importância e o valor das histórias da tradição na educação e nas nossas vidas, enquanto sinalizadores de valores e conhecimentos capazes de religar saberes e experiências de vida. Isso não significa dizer que os professores terão que excluir da sala de aula o conteúdo curricular oficial disposto nos livros didáticos. Não se trata disso. Trata-se da conexão e do diálogo permanente entre os saberes não-científicos, expressos nas narrativas, com os conteúdos escolares, através do uso contínuo das narrativas na escola, e não apenas nos momentos chamados a hora do conto (FARIAS, 2006, p. 22).

É nesse contexto que a relação intersaberes e escolas constituiu-se num espaço que abre a possibilidade de ensinar os sujeitos a história de seu lugar, a sua própria história, entendendo a memória como um ato político, e isso é ensinar a dialogar com o mundo, em que,

Por isso mesmo pensar certo coloca ao professor ou, mais amplamente, à escola, o dever de não só respeitar os saberes com que os educandos, sobretudo os das classes populares, chegam a ela saberes socialmente construídos na prática comunitária mas também, como há mais de trinta anos venho sugerindo, discutir com os alunos a razão de ser de alguns desses saberes em relação com o ensino dos conteúdos (FREIRE, 1996, p. 30).

O contato dos estudantes dessa extensão universitária permitiu aos mesmos conectarem-se com as histórias e memórias do seu lugar e do seu povo. Em Robson Marques, o guardião de histórias abriu-se a possibilidade de diálogo com o mundo e construirmos uma educação que leve em consideração o contexto das vidas e histórias dos sujeitos.

\subsection{De poeta à paleontólogo da tradição}

Robson Marques, guardião do Vale dos Dinossauros em Sousa/PB, Alto Sertão Paraibano, chamado de "Velho do Rio", poeta, cronista, um verdadeiro intelectual da tradição nas palavras de Conceição Almeida em "Saberes Científicos e Saberes da Tradição". Aos 72 


\section{Revista
Debates Insubmissos}

anos de idade, o velho rio, com a sua sabedoria, vem escrevendo poesias e crônicas que tratam do seu cotidiano e de suas experiências com a natureza.

Desde 1975, Robson, às margens da bacia do Rio do Peixe, relembra que morava com a sua família na fazenda Jaganda, localizada a há aproximadamente $8 \mathrm{~km}$ da cidade de Sousa/PB. Foi nesse ambiente que Robson escutava as histórias de trancoso contadas por seus parentes. Ainda jovem começara a escrever seus primeiros versos. Sua história com o Vale dos dinossauros inicia com o seu avô Anisio Fausto, em 1897, agricultor e tropeiro viajante identificou rastros que na época eram considerados de boi ou de ema. Porém anos mais tarde chega a cidade de Sousa/PB o paleontólogo Giuseppe Leonardi, italiano que aprofundará as investigações dos fósseis e espécies das pegadas, comprovando-as serem de dinossauros. Robson tomou para si essa descoberta como uma missão, da qual o tornou guardião do que atualmente se configura como Vale dos dinossauros.

Cronista, poeta, artista plástico, cordelista, não cansa de dizer que o que move é a necessidade de conhecer a vida. Sua participação no projeto de extensão, ora tornado artigo, foi de suma importância para que os alunos acessassem outros domínios do conhecimento. Ele acredita que se a poesia e a literatura ganhassem mais espaço na educação das pessoas, seríamos mais criativos, inventores. Seus escritos apostam num mundo mais justo e solidário. Alguns versos desse poeta que prefere as rochas como projeto de vida.

\footnotetext{
O Vale dos Dinossauros é seu

É meu, é da Humanidade

Por isto todos somos responsáveis

Pelos destinos ávidos desta cidade

Que ela tenha dias ufanos e preclaros

Nossa terrinha onde viveram os DINOSSAUROS!
}

Ao nos reunirmos com os jovens extensionistas, com Robson, e com os professores da rede básica de ensino em Sousa/PB, observamos a necessidade de inserção da história do Vale dos dinossauros no currículo da Educação básica em Sousa. O Vale por meio das memórias do velho se torna um campo de estudo para historiadores, geógrafos, assistentes sociais, antropólogos, e demais interessados. Robson tem construído uma crítica de que as escolas e as 
universidades esquecem de contar as histórias que seus antepassados têm. Para ele elas tem se preocupado demais em formar para o vestibular, para o ENEM, e esquecido de formar pessoas de sabedoria. Alguns professores atentamente se prontificaram a inserir alguns dos escritos do velho em suas disciplinas.

\subsection{O Vale dos dinossauros: o habitat das ideias de Robson Marques - o velho do Rio}

O Vale dos Dinossauros é um sítio geológico e paleontológico localizado na bacia do Rio do Peixe na cidade de Sousa/PB. Seu reconhecimento enquanto monumento natural se deu pelo Decreto $n^{\circ}$. 23.832/02, legitimando-o como um bem patrimonial de significativo valor histórico, científico, cultural da cidade sertaneja. Há estudos já desenvolvidos sobre o Vale numa perspectiva de implementar políticas culturais conforme Silva (2009), o que percebemos ser de grande riqueza para a ciência pois denuncia o descaso do poder público e da sociedade na defesa da valorização por meio de práticas preservacionistas do Vale. Nossa proposta de estuda concentra-se em três categorias de análise: os saberes da tradição, a memória social (neste caso a figura mitológica do velho do rio) e a cultura popular com enfoque no aspecto educacional.

Nomeamos o projeto a partir de "Alice no País dos Dinossauros". Esta ideia surgiu das conversas com o Robson Marques, o Guardião do Vale que afirmou a presença de uma menina Alice que visitou o Vale e o apelidou de "velho do rio". A partir deste achado, observamos que há uma necessidade maior de divulgação do conhecimento sobre o Vale dos Dinossauros, tomando como apoio a experiência de vida de Robson Marques que há mais de 20 anos constrói sua história no compasso da história do Parque. Uma maneira de produzir este conhecimento seria desenvolver uma escuta sensível do ator em questão, procurando mapear os saberes da tradição ou populares que circunscrevem a história da cidade. Assim, defende-se a visibilidade dos saberes da tradição como complementares ao conhecimento científico, visto que a Universidade não é a única promotora do conhecimento. Como nos aponta Almeida (2001, p. 15):

Não é exagero afirmar que a estrutura universitária tornou-se pesada demais para responder a contento, até mesmo ao papel que ela própria atribuiu. Mas, como em todo processo de "auto-organização pelo ruído", o isolamento e a autofagia acabaram por nos permitir enunciar o paradoxo no qual estamos imersos. Em parte 


\title{
noviste \\ Debates Insubmissos
}

\begin{abstract}
desvinculada da sociedade; por vezes em antagonismo com outros espaços de produção do saber; montada em estruturas burocráticas auto-centradas (sic) e sem conexões; seccionando por força do poder estatutário, atividades inequivocamente inseparáveis como ensino, pesquisa e extensão; subsumindo a vocação prazerosa e ancestral do conhecer em estruturas de "cargos", "carreiras", e "regimes de trabalho"; propugnando de forma redutora e utilitarista pelo predomínio da resposta técnica sobre a especulação, da explicação sobre o entendimento, e assim por diante, a estrutura universitária tem se tornado, em grande parte, um empecilho para o pensamento criativo e libertário.
\end{abstract}

A experiência em questão permitiu criar um itinerário de formação humana capaz de politizar o conhecimento, tornando demasiadamente humano, como se dá na relação entre vida e ideias, literatura e ensino que podem funcionar como caminhos para a imaginação poética e com o cuidado com o outro e com o planeta. Estes mecanismos podem também motivar a organização dos atores sociais e culturais que constituem a vida dos sousenses. O que nos permitiu ancorarmos os saberes da tradição do velho do rio e do Vale dos Dinossauros, com a memória, que guarda o ambiente, as emoções das pessoas que olham e tocam as paisagens e fósseis do Vale dos Dinossauros. Isto tem por base a Constituição de 1988, cidadã, que propõe em seu artigo 216 a noção de Patrimônio cultural brasileiro: "Constituem patrimônio cultural brasileiro os bens de natureza material e imaterial, tomados individualmente ou em conjunto, portadores de referência à identidade, à ação, à memória dos diferentes grupos formadores da sociedade brasileira...”. Entendemos que é na memória que são guardados os sentimentos aos lugares, as pessoas. Como também os conhecimentos de mundo, a história que se faz no natural e reflete na vida social local como defende Maia (2003).

Sendo assim as ideias que fundam este projeto apontam para ação extensionista que tem como atores as memórias do guardião do patrimônio histórico-cultural, a educação pública municipal e estadual de Sousa/PB e a cultura local com as suas experiências sociais. Tudo isto recoloca no centro do debate sobre a educação contemporânea o que queremos ser no futuro? Uma sociedade que se intelectualiza e troca a memória das histórias e mitos do cotidiano pela ciência dogmática e sem consciência? Logo, faz-se necessário uma re-ligação dos saberes aqui em jogo, a paleontologia, a geografia, as ciências humanas e exatas, as experiências sociais, para uma leitura das ideias na vida. Assim como contribuir com a formação de um currículo complexo que leve em consideração as histórias pessoas dos sujeitos, com vistas a um conhecimento pertinente. Sidnei completa: 


\title{
nevistet \\ Debates Insubmissos
}

\begin{abstract}
Tomando a história do currículo, não é difícil constatar-se que este artefato social, esta "tradição inventada", vem servindo predominantemente ao príncipe, não estamos com isso, acreditando ingenuamente num currículo que não represente uma mobilização do poder em favor de um processo hegemônico, o que preconizamos por princípios, é a instituição de práticas curriculares que se densifiquem como práticas de liberdade. $(\mathrm{S} / \mathrm{D})$
\end{abstract}

\section{METODOLOGIA}

Esta proposta não se trata de um método fechado, mas de uma metodologia de ação que visa em sua intenção primordial a transformação dos sujeitos envolvidos. Como fundamento teórico-metodológico toma-se a Educação Popular e Dialógica, tendo como expoentes os estudiosos Thiollent (2008) e Morin (2001). Pois em uma ação social e cultural há uma relação com a transdisciplinaridade.

$\mathrm{Na}$ primeira fase, realizamos as visitas aos atores coletivos deste processo, ao velho do rio, ao Vale dos Dinossauros, e às escolas municipais e estaduais em sua totalidade três, Escola Estadual Júlio Sarmento, Escola Estadual Batista Leite e Escola Municipal Maria Aurita. Neste primeiro momento realizamos uma divulgação do projeto junto às instituições parceiras, motivando um processo de participação e diálogo.

$\mathrm{Na}$ segunda fase, observamos os ambientes, fazendo escuta e propondo a criação de instrumentos como oficinas de saberes, entre os estudantes da Universidade envolvidos no projeto com os estudantes das escolas. Registramos as vivências com as imagens do natural e das experiências sociais.

$\mathrm{Na}$ terceira fase, promovemos um encontro entre o Guardião do Vale dos Dinossauros com os docentes das escolas para a construção de um currículo cultural, afim de inserir nas disciplinas a relação com o patrimônio histórico cultural que é o vale, desenvolvendo nos educadores a sensibilidade humana e um olhar de pertencimento ao local com vistas a educação contextualizada.

$\mathrm{Na}$ quarta e última fase, elaboramos o relatório final, com os encaminhamentos realizados pelos participantes da ação extensionista, os quais escreveram seu depoimento de vivência nesse projeto de extensão. 
A metodologia de extensão embora se necessite desta sistematização está aberta aos imprevistos do cotidiano dos sujeitos. Sendo participativa e baseada no diálogo.

\section{DEPOIMENTOS, VIVÊNCIAS DE EXTENSÃO UNIVERSITÁRIA}

Como parte dos resultados e análises desse projeto de extensão optamos por apresentar os depoimentos dos estudantes extensionistas que passaram mais de uns anos em contato direto com as escolas e com sabedoria do guardião do Vale dos dinossauros.

\section{Aluna Joelma Santos (Curso de Serviço Social)}

O projeto "Alice no país dos dinossauros" foi de suma importância para adquirir novos conhecimentos acerca de uma cultura popular de um sertanejo sousense, de acordo com suas vivências e experiências do cotidiano que são postas em prática todos os dias com muita dedicação e amor. Onde o "velho do rio" passa a maior parte do seu tempo dedicando se a expor por meio de conversas e contos a grande importância para a população como um todo, e para o nosso país, porém a cultura local não é valorizada o quanto deveria.

O grupo de estudo tinha como proposito discutir o tema acima citado por meio da transdisciplinariedade, indo além dos muros acadêmicos, para que assim viesse ocorrer uma discussão sobre o fazer ciência como algo que pode se concretizar por meio de experiências vividas, embora seja importante um certo rigor no assunto do qual foi estudado. Não existe verdade absoluta e imutável, a ciência é importante, bem como, a filosofia, teologia. O conhecimento pode ser adquirido de diversas formas, seja por meio de um rigor científico ou através de uma roda de diálogo com colegas.

A articulação transdisciplinar como as escolas públicas foi de grande contributo para aprender e repassar conhecimentos. Buscou se a interação com os alunos de forma clara e objetiva, por meio de narrativas, e a encenação de um pequeno teatro, para facilitar a compreensão do que se queria expor, para todos e todas e qual seria a importância da figura do "velho do rio" Robson Marques, bem como, a preservação do vale dos dinossauros enquanto patrimônio histórico e cultural da cidade de Sousa no Estado da Paraíba. 
Diante do exposto e de tudo que foi estudado discutido e colocado em prática, foi de bom grado e aprendizado não apenas pela participação de um projeto para o enriquecimento acadêmico, mas também como experiência vivida.

\section{Aluna Kamilla Gomes Medeiros (Curso de Serviço Social)}

As reuniões sempre pautadas nas contribuições que o Vale dos Dinossauros trouxe, e traria ainda, devido sua importância histórica e cultural muitas vezes desconhecidas pelos que residem na cidade de Sousa-Pb, contribuições essas trazidas também por Robson Marques, ser humano louvável que não se acanhou em nossas visitas em repassar sua sabedoria acerca do local e de tudo que ele observava com sua visão diferenciada sobre o mundo.

Eu tive a oportunidade de participar de duas das quatro oficinas desenvolvidas pelo nosso grupo. A primeira oficina consistia em apresentar um teatro de fantoches para as crianças de uma escola municipal de Sousa, onde levaríamos a história do Vale dos Dinossauros para elas que se mostraram bem atentas fizeram ressalvas durante nossa apresentação e podíamos constatar que uma significativa parcela nunca tinha ido até lá. Minha segunda oficina se deteve à adolescentes de uma escola estadual do mesmo município, na qual levamos como tema principal os estereótipos impostos pela sociedade atual que inclusive nessa fase da vida ganha uma grande evidencia gerando assim uma cobrança irrefutável e injusta para com aqueles que ainda se encontram em formação, interna e externa. Nas duas apresentações fomos muito bem recebidos e houve a troca indubitável de conhecimentos.

Para mim fazer parte desse seleto grupo do Projeto de Extensão “Alice No País dos Dinossauros" foi uma honra, aprendi muito e esses conhecimentos refletirão com toda certeza na minha vida profissional, apenas aguçou ainda mais a minha vontade de fazer parte de mais projetos como esse durante minha vida acadêmica.

Participar do projeto de extensão "Alice no País dos Dinossauros", foi uma experiência e um período de grandes contribuições para tanta vida acadêmica e profissional. Os textos e as discursões sobre os mais variados assuntos, o diálogo com profissionais de outras áreas me ensinou a importância da interdisciplinaridade e o respeito às outras opiniões. 
Além disso, aprender a história, conhecer mais uma vez as trilhas, as pegadas, fazer uma viagem no tempo, valorizar o legado histórico do Vale dos Dinossauros e poder repassar para as crianças, por meio da oficina de Paisagens Sonoras, realizado na EMEF Maria Aurita da Silva, através do teatro, slides com fotos, contando para as crianças a história do Vale e ainda, foi uma experiência única.

Assim, reitero que o projeto de extensão: "Alice no País dos Dinossauros" trouxe grande aprendizado para formação acadêmica e profisssional, como também apreensão da história e importância do Vale para nossa cidade, com o retorno positivo das crianças e professora que se fizeram presentes na aplicação da oficina.

\section{Aluno Luis Alberto (Curso de Direito)}

Fomentar o conhecimento é dar asas à imaginação. A partir da participação no Projeto de Extensão, intitulado: "Alice no País dos Dinossauros" tivemos a oportunidade de vivenciar um misto de experiências bastante enriquecedoras, construtivas, e ao mesmo tempo significantes para o processo de aprendizagem acadêmica, bem como, como parte do meio em que estamos inseridos.

De início, cabe falar um pouco da importância assumida pela extensão no que tange a relação com a sociedade. Levar o conhecimento construído na universidade para além dos muros desta própria instituição mostrou-se como tarefa indispensável para nossa formação enquanto acadêmicos e extensionistas, como também para o convívio social, uma vez que nas reuniões mantidas pelo projeto, aprendemos a trabalhar em grupo, debater pensamentos e opiniões, planejar ações de intervenção junto à comunidade, acrescentando-se a isto, o conhecimento disseminado entre os próprios integrantes do projeto e o compromisso de difundir essa experiência para com a sociedade.

Durante o momento de planejamento e discussões em torno da temática abordada pelo projeto, discutimos meios e ferramentas de levarmos o conhecimento para a sociedade; palestras, dinâmicas, vídeos, tudo isto, possibilitou o alcance de nossos objetivos, bem como as funções atribuídas a cada membro do grupo. 
Ao perseguirmos a linha de estudo abordada pelo projeto, adquirimos uma gama de conhecimentos que foram se ramificando em outras áreas, conhecemos um pouco da interessante história do Vale dos Dinossauros (patrimônio histórico e cultural do Município de Sousa/PB), suas peculiaridades, bem como a história de vida de Robson, enquanto expectador do meio em que o Vale se formou.

Um ponto que nos chamou bastante atenção, foi o fato da interdisciplinaridade do projeto com outras áreas do conhecimento; a conjuntura assumida por este, nos possibilitou trabalhar nas oficinas com assuntos e temáticas cada vez mais diversificadas, merecendo um toque especial neste relato, à experiência vivenciada pela apresentação da Oficina "Educação Física, competição e cooperação", sob o sub tópico: Estética e Saúde.

De início, podemos dizer que tivemos um pouco de insegurança no que tange ao interesse dos alunos, ao que seria exposto no debate, mas tal sentimento foi passageiro, ao começarmos a expor de forma dinâmica o conteúdo os alunos sentiram-se a vontade para intervir na exposição, deixando a oficina ainda mais construtiva e fomentadora de questionamentos. Em um momento posterior fizemos um intervalo, abrindo espaço para que o público alvo, mais especificamente o $2^{\circ}$ ano do Ensino Médio da Escola Poli II, tivessem um contato mais estreito com o nosso grupo. A partir desse momento, os adolescentes (alunos) começaram a falar sobre assuntos variados, perguntando-nos como era a vida na faculdade, qual curso estudávamos, por que estávamos apresentando tal palestra para eles, e isso foi de estrema importância para que mantivéssemos um elo de intimidade com aqueles que estavam nos escutando.

Na oficina em si, cada integrante do grupo se apresentará e posteriormente começamos a ministrar nossa palestra, de início, contextualizando uma evolução histórica no que concerne aos padrões estéticos e físicos ao longo do tempo, depois, adentrando no debate de que, os padrões estéticos e o conceito de beleza são determinados culturalmente pela sociedade, já que com o passar dos anos este conceito veio sofrendo transformações, nos levando a máxima de que "o que era considerado bonito e valorizado em determinado época, poderia não ser na atualidade, já que tais conceitos estão sob constantes modificações". 
Em momento distinto, adentramos no tema: "A alimentação saudável e os métodos inapropriados utilizados por grande parte da população na busca por um corpo perfeito", atentando-se aqui, a conscientizar aos adolescentes quanto à prática de exercícios físicos aliados com uma boa alimentação, visando à formação de uma consciência comprometida com a qualidade de vida e com o bem-estar das pessoas.

Por fim, falamos um pouco sobre a importância da desconstrução de estereótipos, assumindo a premissa de deixar claro que nem sempre pelo fato de que uma pessoa seja "gordinha", isto necessariamente queira dizer que ela não seja feliz, pelo contrário, é amando o seu corpo que a pessoa deve procurar melhorias para sua saúde e consequentemente para sua vida, entendendo que nem sempre por ser uma pessoa magra ou sarada (padrão difundido pela mídia e a sociedade), consequentemente isto seja sinônimo de felicidade.

O projeto Alice no país dos dinossauros resgatou-me a um contexto histórico muito grandioso de minha cidade natal, pode trazer de volta tamanha cultura que por vezes não é valorizada ou até mesmo desconhecida me fez transbordar de tamanha gratidão em fazer parte desse projeto. O projeto como já mencionado transborda também apenas o caráter cultural e atinge a área acadêmica com sua interlocução entre cursos da UFCG campus Sousa.

O poder que a aproximação que a cultura nos causa remete-nos a pensar porque não antes, mas participar de um projeto de extensão que foi pensado por um professor brilhante e minha fonte de inspiração dentro da universidade, que é o professor Luan Gomes, é de tamanha valia que em palavras não se consegue expressar.

As oficinas que foram construídas a partir do projeto foram coisas lindas e de grande conteúdo valorativo e de aprendizado, a que fiquei inserida, de levar a história do vale para uma escola de nível fundamental, onde se deve cada vez mais se investir em cultura, pois estamos falando de crianças com inteligências que nossas meras percepções são incapazes de vislumbrar é de suma importância, a oficina foi um sucesso e pudemos transmitir o que queríamos naquele momento a importância desse patrimônio histórico para a cidade de Sousa na Paraíba que é o vale dos dinossauros. 
Finalizo deixando meu agradecimento por ter tido a honra de participar desse projeto desde seu processo embrionário até seu nascimento, o Vale dos Dinossauros merecia essa atenção e foi o que nos debruçamos a fazer, dar visibilidade ao Vale e a quem tanto lhe dedicou amor e tempo, Seu Robson, o Velho do Rio.

\section{Aluna Francisca Daniele da Silva (Curso de Serviço Social)}

Ao tempo em que cumprimento Vossa Senhoria, encaminho o Relato das experiências vivenciadas ao longo do Projeto de Extensão “Alice no País dos Dinossauros": memória e cultura popular de um sertanejo sousense.

O projeto acima intitulado foi muito proveitoso, de forma que me possibilitou ir além do que imaginava que poderia conseguir. Mesmo diante das adversidades que sempre surgiam ao longo desse processo, pois eu conciliava estudo das disciplinas da faculdade, estágio e projeto de extensão, para muitos parecia uma tarefa um pouco árdua, mas para me foi muito gratificante, pude contar com pessoas que me apoiava e me incentivava a sempre seguir nos meus objetivos, acreditando sempre que, tudo é possível para aquele que crê, só basta ter FORÇA, FOCO E FÉ.

Bom, participar desse projeto me fez vê que a união faz a força, e que juntos podemos ser fortes, embora não tenha participado de nenhuma das oficinas, confesso que não foi por não querer, pois busquei me organizar com o grupo a que me enquadram, porém houve uma certa resistência em querer se articular com os membros que se interessavam e assim, como uma "ovelha só não faz verão", a oficina não foi planejada e muito menos executada.

Conviver nesse período com vocês foi ótimo, apesar de que muitas das vezes ter que sair mais cedo, por causa do transporte que dependia para voltar. E como as reuniões sempre começavam um pouco mais tarde, tornava inviável a minha permanência até o termino, mas sempre procurava ficar a pá de tudo que acontecia nos encontros, sempre lendo os textos propostos e acompanhando a visita ao Vale dos Dinossauros. Ficou a saudade de tudo que vivemos juntos, os momentos partilhados, cada risada, cada conversa, tudo isso ficou e ficará guardado em meu coração. 
A minha participação nesse projeto de extensão, me possibilitou compreender a quão grande relevância patrimonial, cultural e histórica está presente no vale, que pena que é tão pouco estudado e divulgado como deveria, seja nas escolas ou nas repartições públicas da cidade de Sousa.

Essa oportunidade de convivência e envolvimento com a realidade social e cultural dessa cidade me instigaram a tantas interrogações e inquietações, do por quê do descompromisso dos governantes com o vale dos Dinossauros, o qual deveria ser investido, o que possibilitaria um crescimento da cidade de Sousa, bem das cidades circunvizinhas, essas possiblidades podem ser discutidas ao longo das aulas nas escolas como forma de dá a devida importância ao maior parque paleontológico do Brasil e tornar a participação mais responsável pela gestão pública.

Fazer parte dessa equipe do projeto de extensão "Alice no País dos Dinossauros" contribui para que tenhamos uma formação articulados a novos saberes, proporcionando um olhar mais apurado da realidade a que estamos inseridos/as, através das experiências compartilhadas e das ricas vivências ao longo do referido projeto. Obrigada!

\section{Aluna Segislane Moésia P. da Silva (Curso de Serviço Social)}

A extensão por fazer parte do tripé de constituição do ensino na universidade, é de fundamental importância para o aprendizado do aluno, é onde vivenciamos experiências únicas, onde podemos levar a campo nossos conhecimentos e principalmente onde podemos interagir com outras pessoas, seres humanos.

O projeto Alice no País dos Dinossauros agregou valores únicos em minha pessoa, no sentido tanto de conhecimentos teóricos com relação aos livros, textos e ensinamentos do professor Luan Nasa, quanto a extensão propriamente dita. Essa relação de trazer o conhecimento para a prática deixa tudo mais leve, mais saboroso de ser estudado.

A relação do projeto com a história do vale dos dinossauros com o Sr. Robson - quem fascinava a todos quando recitava seus poemas ou até mesmo contava suas histórias - traz algo mais do que se considera como ciência. O projeto mostrou claramente a ideia de que a ciência, o conhecimento e o que se denomina "senso comum" andam lado a lado e que não 
podemos desprezar CONHECIMENTO algum. Toda experiência é uma forma de conhecimento, vimos o Sr. Robson, um senhor simples e humilde que se dedicou a vida inteira a cuidar do vale dos dinossauros na cidade de Sousa, que expressa suas emoções e criatividades em forma de escrita, de poemas, versos ou simples palavras, contudo, mesmo não sendo considerado um teórico ou cientista, possui uma carga de conhecimento absurda e que nos proporcionou uma experiência única.

Enfim, a aplicação da oficina na qual fiz parte, foi ótima, permitiu contato com pessoas e principalmente permitiu repassar um pouco desse conhecimento que adquiri ao longo do projeto. O projeto foi realizado durante um período consideravelmente bom, contudo, já deixou saudades e só tenho a agradecer ao mestre Luan por me permitir ter feito parte desse projeto. Desde já, obrigada!

\section{Aluna Jéssica Fernandes da Silva Nascimento (Curso de Serviço Social)}

Este parecer tem por finalidade mostrar a apreensão do projeto de Extensão "Alice no País dos dinossauros", a participação no mesmo foi muito importante, pois faz um resgate sócio-histórico e cultural do que representa o Vale dos Dinossauros na cidade de Sousa e para a população em si. Foram desenvolvidas atividades pedagógicas, oficinas, em que organizei junto a minhas colegas a junção da arte, teatro, música, história local e slides de paisagens sonoras.

A aplicação desse projeto objetivou expor a valiosa riqueza e patrimônio histórico cultural do vale, que traz em sua bagagem um arcabouço de contribuições genuínas para SousaPB a nível internacional extremamente peculiar. Através da literatura de cordel, música, teatro, história repassamos aos nossos meninos a importância deste bem, contido na cidade sorriso onde me faço satisfeita com a compressão do objetivo do projeto pelo público alvo.

Para a formação acadêmica é imensurável as contribuições sobre a caracterização do espaço onde se encontra a universidade, conhecimento local e cultura, visto que universidade, pesquisa e extensão são um tripé inseparável. Através das oficinas pudemos fazer uma retroalimentação da universidade com a sociedade difundindo um saber cultural, pois as pessoas necessitam também de riqueza intelectual para sentirem pertencimento ao local que 
estão, e este projeto veio mostrar as riquezas sócio-históricas do Vale dos Dinossauros para dar rosto à cidade sorriso, mostrando também como é importante valorizar. Essas atividades em grupo foram substanciais para meu envolver com outras pessoas de outras áreas e tudo que foi arquitetado me fez relembrar sobre a carga cultural tão esquecida por muitos que norteia a nossa região e como é importante essa cultura como identidade de um povo. Ressalva-se também a figura de seu Robson, o guardião e a história viva do Vale dos Dinossauros que como este projeto se reforçou mais ainda o que muitos não conheciam ou até mesmo já haviam esquecido, sobre o famoso velho do rio.

Acredito que tudo que se tem a oportunidade de fazer pela sociedade num projeto de extensão e pesquisa, é sempre uma forma de aprendizado que soma para ambos, estudante e sociedade.

\section{Aluna Maria Romilda Coelho Fernandes (Curso de Serviço Social)}

O desenvolver do projeto em questão foi de grande relevância para toda a equipe participante. A proposta inicial foi a de desenvolver um projeto por meio de uma partilha dialógica com vistas a trazer maior interação e aproximação com os saberes construídos na universidade, e os saberes populares construídos em torno do patrimônio cultural e de preservação "Vale dos Dinossauros" na cidade de Sousa - PB. O projeto propunha desenraizar nos pesquisadores o maior desejo de aproximação com os saberes populares como forma de ampliação dos conhecimentos acadêmicos, nesse caso, através de narrativas de histórias vividas pelo senhor Robson Marques, "o velho do rio".

No primeiro momento a equipe participou de vários encontros, onde se promovia através de diálogos, uma maior aproximação com o tema: conhecer e se apropriar dos fatos históricos e dos cientificamente ligados a área de preservação do vale dos dinossauros, ao mesmo tempo em que, interagíamos com a cultura local a fim de entender melhor as construções das narrativas populares acerca das histórias do vale dos dinossauros. O professor Luan (coordenador do projeto) proporcionou através do projeto uma junção de alunos de cursos diferenciados, Serviço Social, direito e etc. O que fez com que percebêssemos a importância de uma transdisciplinaridade na construção de pesquisadores que vão além do 
que está posto teoricamente e criam instrumentos capazes de alcançar a vida e cultura popular. Acima de tudo sensibilizados e mobilizados na preservação de patrimônios culturais e sociais. Participamos ainda de reuniões com docentes e pesquisadores de áreas afins. Nas reuniões despontava-se desde as mais simples conversas até os mais acirrados debates, onde sempre chegávamos a um consenso e a construção de saberes fortalecidos no diálogo e nas experiências vividas. Houve também a aproximação e revisão de literaturas relacionadas, o que a meu ver poderia ter sido mais ampliada, tendo em vista que tivemos a aproximação com poucos autores, dentre os quais pode-se citar Edgar Morim, Capra, Almeida e os escritos do próprio "velho do rio", Robson Marques. Tal fato talvez se justifique pelas especificidades que permearam o ano letivo na UFCG Campus Sousa PB. No entanto, as aproximações literárias e pedagógicas nos permitiram a construção de opiniões teoricamente fortalecidas acerca do tema.

No segundo momento, atendendo a mais um eixo proposto no projeto, a equipe extensionista participou de visitas ao Vale, visando agora captar através de uma escuta e de uma observação sensíveis, às histórias relacionadas ao local, algumas vivenciadas e construídas em torno do "velho do rio" Robson Marques. Nos encontros os discentes se mostraram interessados pelo tema e vários questionamentos foram feitos ao Sr. Robson, que os respondia com entusiasmo e sabedoria, transmitindo para a nova geração acadêmica, histórias pitorescas e contos populares que circunscrevem a história do vale e constroem a própria história da cidade de Sousa. Nas visitas tivemos a oportunidade de registrar através de fotos, e relatórios escritos, as imagens da natureza, que por si só contam essa história.

As oficinas foram construídas a partir desses encontros, sempre com temas relacionados ao eixo temático principal: cultura, memórias e educação. A importância da aproximação da universidade com a sociedade dá-se pelo fato de construir pesquisadores capazes de participar da construção de novos saberes, sem, no entanto, dissociar esses saberes dos saberes populares.

As demonstrações das oficinas foram feitas em escolas locais, sendo municipais e estaduais, o que proporcionou as equipes extensionistas a oportunidade e o compromisso de criar, dialogar, produzir e expandir as memórias relacionadas ao Vale dos Dinossauros a partir 
do "Velho do Rio", para os alunos das escolas primárias. Como discente do curso de serviço social, tive a oportunidade como um momento de grande relevância para a minha formação acadêmica. Foi gratificante levar aos alunos da rede pública de ensino a oportunidade de crescerem pedagogicamente valorizando mais a cultura local, e de sensibilizá-los à importância de preservar as memorias populares e os saberes que constroem nossa história e riqueza cultural.

Por fim vimos a importância de levar para além das paredes da universidade o conhecimento adquirido e a oportunidade de fazer com que esse conhecimento possa agregar, construir e abrir os horizontes da cultura popular, e não a extinguir a partir das novas teorias. E como diz Pulo Freire: "devemos mostrar essa relação de forma humilde e humanizada".

\section{Alunas Brenda Larissa e Camilla Gomes}

No dia 14 do mês de abril de 2016 teve início por volta das nove horas da manhã a aplicação da oficina Cultura e Direitos Humanos, aplicada com a turma do $3^{\circ}$ Ano A, da Escola Estadual de Ensino Médio Mestre Júlio Sarmento, localizada na cidade de Sousa, Paraíba, executada pelas extensionistas Brenda Larissa Santana Dourado e Camilla Isabely Gomes da Silva alunas do $8^{\circ}$ período do curso de Direito da Universidade Federal de Campina Grande

A metodologia adotada foi a apresentação de vídeos, por meio do qual se suscitou o debate e a reflexão crítica acerca da temática dos direitos humanos e da cultura universal.

Iniciou-se as atividades através da indagação: “o que são os direitos humanos? Sendo ela seguida pela apresentação do vídeo: Você sabe o que são Direitos Humanos? (Pense de novo), vídeo que apresentou conceitos pessoais e a evolução histórica dos Direitos Humanos.

Não houve resposta por parte dos estudantes, então, sugeriu-se a resposta mais comum que direitos humanos são para pessoas direitas, o que é totalmente errado, pois os direitos humanos são universais e independem de cor, religião, nacionalidade ou gênero.

Nem sempre houve direitos humanos e a sua construção deu-se em virtude das violações existentes no decorrer dos anos, culminando na elaboração da Declaração Universal dos Direitos Humanos. A adesão a declaração é opcional. 
Apresentou-se aos alunos o vídeo intitulado "Direitos Humanos em dois minutos" que trouxe o conceito de Direitos humanos. Em seguida foi exposta a Declaração Universal dos Direitos Humanos, em que constam os direitos em questão, apresentando-os e abrindo para possível questionamento a cerca deles.

Em debate nos foi dito pelos alunos que ficaria a cargo da justiça proteger os direitos humanos. Foi esclarecido que o Brasil assinou a declaração dos direitos humanos e por isso tem suas leis baseadas nessa lei, em decorrência dessa assinatura a justiça brasileira cabe julgar os crimes praticados no Brasil, como a violação do direito à vida - por meio da proibição do assassinato, e a dignidade - assegurada pela Constituição Federal, e as violações diretas aos direitos humanos que sendo julgadas no Brasil, não tiveram solução, serão julgados pela corte interamericana de direitos humanos, punindo dessa forma o Estado que viola os direitos humanos e buscando a construção de leis que protejam esses direitos.

Como a adesão a Declaração é opcional apenas se submetem as suas determinações aqueles que a aceitam, no entanto há países que simplesmente a ignoram e deste ponto surgem as violações mais graves como as que ocorrem na Síria e no Iraque. Como está a África nessa situação?

Foi explicado acerca do direito ao asilo político que é concedido à aqueles que sofrem perseguições em seus países de origem devido a sua opinião, ou por ter cometido crime político. Foi-nos questionado acerca dos refugiados, então foi explicada a distinção entre os dois institutos. O asilo é político e é concedido para aqueles que chegam a embaixada brasileira, e pedem asilo por estarem sofrendo perseguição política ou ideológica conseguindo assim o salvo conduto para ser conduzido ao Brasil, já o refúgio é concedido aqueles que não possuem condições de permanecer em seu pais de origem e migram para outros países buscando condições mínimas de sobrevivência, e é concedido ao refugiado que chega ao país que o abrigará.

Foi apresentado por meio da série de vídeos: "Série Direitos Humanos", apresentando situação problema acerca da violação dos direitos humanos, da dignidade, da liberdade e da igualdade. Dessa forma houve participação da turma no sentido de identificar a violação ocorrida. 
Por fim foi possível observar que os alunos puderam construir uma identidade humana e reconhecer o próximo como semelhante, e visualizando a necessidade de proteger os direitos humanos no sentido de não os violar e combater a violação, sendo a oficina encerrada por volta das nove horas e trinta e cinco minutos.

\subsection{O testemunho dos educandos extensionistas como uma experiência pedagógica dialógica}

A verdadeira mão que o poeta estende não tem dedos: é um gesto que se perde no próprio acto de dar-se.

Ana Hatherly, O Pavão negro

A epígrafe acima ilustra de maneira adequada o mosaico de testemunhos apresentados e escritos pelos extensionistas, que ao entrarem em diálogo com o poeta e guardião Robson Marques compreenderam algumas palavras-chaves nos estudos dos saberes da tradição, tais como: narrativas, memórias, direitos humanos, patrimônio histórico e transdisciplinaridade. Os testemunhos revelaram a força da autonomia do pensamento de cada um dos educandos e educandas. Essa autonomia de pensamento é vital para o processo educativo, pois colabora com o despertar de criatividades e com a capacidade de leitura do mundo diversas.

A partir do contato dos alunos com o Velho do Rio, eles recriaram histórias, e puderam dar significado as mesmas de uma forma singular, garantindo um princípio de pluralidade e democracia na produção de saberes. Como sempre lembra Paulo Freire, acerca de observar com cuidado os saberes anteriores dos sujeitos que carregam histórias que vão além das escolas, transformando-as.

Dessa maneira, a experiência de extensão dos alunos revelou-se positiva, pois permitiu a prática do diálogo, da escrita poética, sem deixar o rigor que é necessário a produção do conhecimento. Esta relação entre o poeta e os extensionistas configurou-se como uma atitude dialógica, isto é, sem imposição de conhecimentos, comportando-se como possibilidades de criação de itinerários diversos de aprendizagem. 


\section{PEGAdAS INACABADAS OU AS HISTÓRIAS INCONCLUSAS DO GUARDiÃO DO VALE DOS DINOSSAUROS}

Os artistas, os poetas, e mesmo na ciência, os pensadores não enclausurados nos paradigmas da repetição e da ordem, experimentaram outras verdades.

Ceiça Almeida

A operacionalização desse projeto de extensão universitária nos permitiu repensar a compreensão de Ciência. Essa antes a compreendíamos como algo separado do sujeito que a constrói. A partir de agora, as ciências no plural são compreendidas como um elemento narrativo, como um produto da cultura. Essas estão implicadas nos sujeitos que a constroem.

A base epistemológica que fundamentou esse artigo apostou numa compreensão ampliada da noção de intelectual. O intelectual é aquele que pensa e se engaja no Viver. Também constroem um caminho sistemático de organização de suas ideias. No caso de Robson Marques, o guardião do Vale dos Dinossauros, o mesmo organiza nos livretos de poesias, crônicas, histórias do Vale dos Dinossauros, sua paleontologia. Esse diálogo mantido com o intelectual da tradição permite que a Educação saia dos muros das escolas, das universidades e amplie a pluralidade de conhecimentos.

Os saberes da tradição, tema fundante desse estudo, se configura como estruturas dinâmicas da arché. Comumente são confundidos com coisas ultrapassadas, com o senso comum, com aquilo que deve estar no passado. Mas eles não estacionam aí. Suas bases epistemológicas os tomam como reservas antropológicas. A produção do conhecimento não é reservada somente comunidade dos cientistas, ou dos acadêmicos. Há outros segmentos que produzem conhecimentos, artesãos, agricultores, poetas, artistas, etc.

Compreendemos que a sabedoria do Velho do Rio, como é chamado Robson Marques, pode contribuir com o diálogo entre a diversidade de saberes. Perguntado certa vez se ele era um intelectual, o mesmo afirma: "acho que não sou, prefiro ser um velho trovador, me dá alegria ver o nascimento das palavras".

Logo, a complementaridade entre saberes científicos e saberes da tradição é uma necessidade a ser perseguida nesse estudo. São estratégias distintas de organização do 
conhecimento, mas não são opostas. Isso pode promover uma educação capaz de ampliar retotalizar o antropos, fragmentado pela educação voltada somente ao mercado. O que podemos aprender com as sabedorias dos intelectuais da tradição

\section{REFERÊNCIAS}

ALMEIDA, Maria da Conceição Xavier de. Reforma do Pensamento e Extensão Universitária. In: Revista Cronos, v.2, n.2. Natal: UFRN, 2001, p. 11-22.

ALMEIDA, Maria da Conceição Xavier de. Técnicas de previsão climática no Nordeste do Brasil: uma "ciência neolítica" no século XX. In CONGRESSO LUSO-BRASILEIRO DE HISTÓRIA DA CIÊNCIA E DA TÉCNICA, 1., Portugal. Actas...Portugal: Universidade de Évora e Universidade de Aveiro. Comissão Organizadora do Congresso (Ed.). Évora: S. Reprografia e Publicações da Universidade de Évora, 2001.

ALMEIDA, Maria da Conceição Xavier de. Complexidade, Saberes científicos, Saberes da tradição. São Paulo: Livraria da Física, 2010.

ALMEIDA, Maria da Conceição Xavier de. O Saber Antropológico - complexidades, objetivações, desordens, incertezas. Tese de doutorado em Ciências Sociais pela PUC-SP. 1992.

ALMEIDA, Maria da Conceição Xavier de. Complexidade e cosmologias da tradição. Belém: eduepa; UFRN/PPGCS, 2001.

FREIRE, Paulo. Pedagogia da Indignação: cartas pedagógicas e outros escritos. São Paulo: Editora Unesp, 2000.

FREIRE, Paulo. Pedagogia da Autonomia: saberes necessários à prática educativa. São Paulo: Paz e Terra, 1996.

LÉVI-STRAUSS, Claude. A antropologia diante dos problemas do mundo moderno. São Paulo: Companhia das Letras, 2012.

LÉVI-STRAUSS, Claude. O Pensamento Selvagem. 12 ed. São Paulo: Papirus, 2012.

MAIA, Felícia Assmar. Direito à memória: o patrimônio histórico, artístico e cultural e o poder econômico. Movendo Ideias, v 8, nº 13. Belém, 2003, p. 39-42.

MARQUES, Robson. O Velho do Rio - História dos dinossauros. (S/d)

MARQUES, Robson. Alice no País dos Dinossauros. (S/d)

MARQUES, Robson. Catando orvalho no assoalho de Sousa. (S/d)

MARQUES, Robson. O velho e os Urubus e as duas meninas com amor. Sousa/PB, 2006. 
MORIN, Edgar - Os sete Saberes Necessários à Educação do Futuro. 3. ed. São Paulo: Cortez, 2001.

SIDNEI, Roberto. TRAJETÓRIA, ITINERÁRIO, ITINERÂNCIA E ERRÂNCIA:

PERSPECTIVANDO O CURRÍCULO ENQUANTO CRISÁLIDA. UFBA.

SILVA, Eduardo Pordeus. Políticas Culturais e Economia da Cultura no sertão paraibano: o caso vale dos dinossauros. João Pessoa: UFPB, 2009. (Dissertação de Mestrado em Ciências Jurídicas).

Submetido em: 29/06/2019

Aprovado em: 02/08/2019 